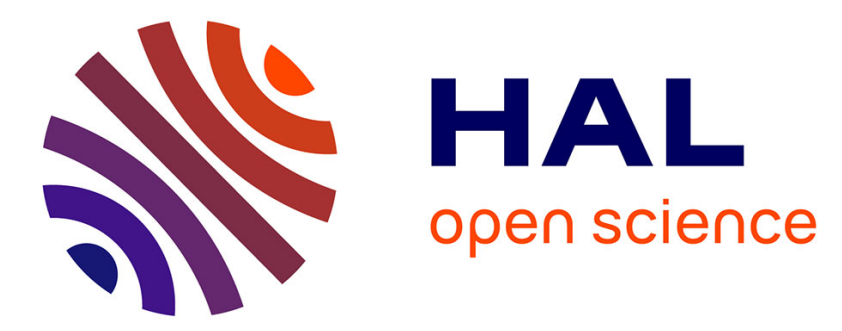

\title{
Identification of the material parameters of soft tissues in the compressed leg
}

\author{
Laura Dubuis, Stéphane Avril, Johan Debayle, Pierre Badel
}

\section{To cite this version:}

Laura Dubuis, Stéphane Avril, Johan Debayle, Pierre Badel. Identification of the material parameters of soft tissues in the compressed leg. 9th Symposium on Computational Methods in Biomechanics and Biomedical Engineering, 2010, Valencia, Spain. p.6. hal-01063519

\section{HAL Id: hal-01063519 \\ https://hal.science/hal-01063519}

Submitted on 12 Sep 2014

HAL is a multi-disciplinary open access archive for the deposit and dissemination of scientific research documents, whether they are published or not. The documents may come from teaching and research institutions in France or abroad, or from public or private research centers.
L'archive ouverte pluridisciplinaire HAL, est destinée au dépôt et à la diffusion de documents scientifiques de niveau recherche, publiés ou non, émanant des établissements d'enseignement et de recherche français ou étrangers, des laboratoires publics ou privés. 


\title{
IDENTIFICATION OF THE MATERIAL PARAMETERS OF SOFT TISSUES IN THE COMPRESSED LEG
}

\author{
L. Dubuis ${ }^{1}$, S. Avril ${ }^{2}$, J. Debayle ${ }^{2}$ and P. Badel $^{3}$
}

\begin{abstract}
Elastic compression (EC) is highly recommended in prophylaxis and treatment of venous disorder of the human leg. However, the exact mechanisms of its action are not enough understood and the response of internal tissues to the external pressure are still partially unknown. A 3D biomechanical FE model for simulating the effect of EC on the human leg has been developed based on the actual geometry of a female leg, obtained from 3D CT-scan images. The model is made up of soft tissues (fat and muscles) and rigid bones. A 2D FE model, reconstructed from MRI, is used to identify the elastic properties of soft tissues by an inverse method. The pressure applied by EC increases linearly from ankle to knee. The results show a non homogeneous pressure field (more than $35 \%$ of discrepancies in a cross section of the leg) bringing evidence that the socks should be adapted to the diseased vein location.
\end{abstract}

\section{INTRODUCTION}

The function of venous return is to bring back blood from organs and muscles to the heart and the lungs. Valves shut to prevent blood from flowing back. But it is not sufficient for the venous return from the legs because they are away from the heart and the blood flow has to fight against gravity. Blood tends to pile up in veins which dilate. Therefore the venous return from the leg is reinforced by the muscular contraction which drains off stagnant blood. The calf is commonly called the peripheral heart: it fills up and empties repeatedly. Venous return of people who have venous diseases or who remain standing, may be not enough and causes varicose vein or oedema in serious cases.

The recommended treatment for venous insufficiency is to wear EC socks. But the response of internal tissues to an external pressure is still partially unknown. Numerical studies have been dedicated to know the pressure of compression garment transmitted to the body (leg, foot or breast) [1, 2, 3, 4] where the mechanical interactions between the body and the garment were modelled. In those studies, soft tissues are defined as homogeneous, isotropic and linearly elastic biomaterials. Another approach is to study the blood flow in veins numerically [5, 6] or experimentally [7], or in muscles during contraction [8].

The aim of this paper is to present a patient-specific 3D FE model of a human leg under EC. After detailing the 3D FE model and the identification of soft tissues constitutive properties, the results obtained on a volunteer are presented.

\footnotetext{
${ }^{1} \mathrm{PhD}$ student, Center for Health Engineering, École des Mines de Saint-Étienne, INSERM IFR 134, PECM CNRS UMR 5146, France

${ }^{2}$ Associate Professor, Center for Health Engineering, École des Mines de Saint-Étienne, INSERM IFR 134, PECM CNRS UMR 5146, France

${ }^{3}$ Associate Professor, Center for Health Engineering, École des Mines de Saint-Étienne, INSERM IFR 134, LPMG CNRS UMR 5148, France
} 


\section{FINITE ELEMENT MODEL}

\subsection{Geometry and meshing}

Image Acquisition. 3D CT-scan images of the leg were acquired on a 25 year old female volunteer without venous pathology. Scans were acquired with and without EC in seated position. The images were segmented in three regions: adipose tissue (skin and fat), muscles and bones (tibia and fibula). Segmentation was achieved using the IMAGEJ software.

Mesh generation. The soft tissues were meshed with 359, 374 tetrahedral linear elements and 71,960 nodes. The mesh was created after image segmentation using the AVISO ${ }^{\circledR}$ software, and exported to the ABAQUS ${ }^{\circledR}$ software for FE computations.

\subsection{Model specification}

Boundary conditions. All the degrees of freedom along the contours of the bones were fixed, as both bones are assumed to be infinitely rigid (their elastic properties are nearly 1000 times larger than those of soft tissues). A pressure was applied on the external surface of the leg. Unlike usual compression, the maximal compression of the socks used for this study is at calf and not at ankle [9]. The pressure increases linearly from ankle $(1.4 \mathrm{kPa}$ in mean) to knee $(4.8 \mathrm{kPa}$ in mean). Pressure values were obtained from the Laplace's law:

$$
P=\frac{T}{R}=k \frac{\varepsilon}{R}
$$

with $P$ the pressure, $T$ the sock tension, $R$ the local curvature radius of the leg, $k$ the fabric stiffness, and $\varepsilon$ the sock strain. The latter was derived knowing leg and sock perimeters from the CT-scans.

Friction of the sock on the leg is neglected, which means that no tangential stress is considered.

Sock characterization. A nondestructive system (Fig. 1) based on the NF G30-102 standard [10], was used to reproduce loading conditions similar to those observed when the sock is worn. The value of $k$ was estimated with an accuracy of $14 \%$.

Material properties. Soft tissues (adipose and muscle tissues) were defined as homogeneous, isotropic and linearly elastic materials. The material properties were identified by an inverse method, detailed in the following paragraph.

\subsection{Identification of soft tissue properties}

For the sake of simplicity and computation time, identification of the soft tissues properties was made on a $2 \mathrm{D}$ model with a custom made routine $[11,12]$.

2D geometry and meshing. MRI scans of the leg cross section were acquired with a $1.5 \mathrm{~T}$ MRI scanner. The cross section considered in this $2 \mathrm{D}$ approach is located at the largest 

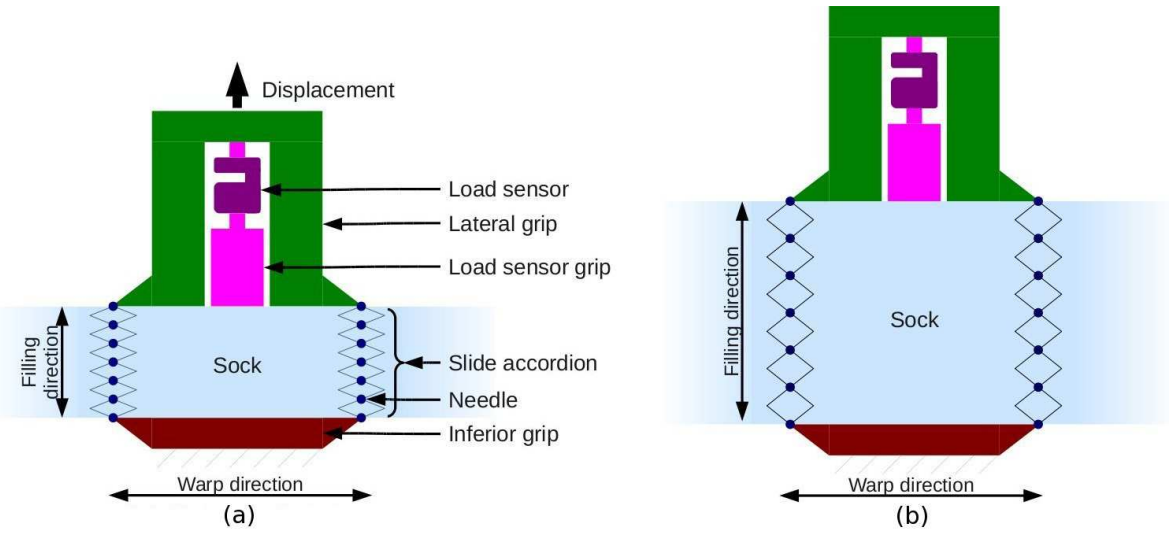

Figure 1: Tensile test of the socks: (a) Unloading state. (b) Loading state. Lateral needles and slide accordion are used to prevent the sock from stretching in the warp direction, which is close to the actual deformation.

calf perimeter. Using a MATLAB ${ }^{\circledR}$ routine, adipose tissues, muscles and bones were segmented and meshed with 400 displacement-based linear triangular elements, which appeared to be satisfactory for the soft tissues considered here. Then the mesh was exported to the FE code. The plane strain was assumed for the $2 \mathrm{D}$ model.

Boundary conditions. As in the 3D model, all the degrees of freedom along the contours of the bones was fixed. The pressure applied along the external surface of the leg was computed using the Laplace's law (equation 1).

Material properties. The response of the soft tissues of the leg was assumed compressible elastic as the finite deformations of the soft tissues remain relatively small (5\%).

Parameter identification. In order to identify the material properties of soft tissues, an image processing approach based on image warping (also called image registration) was used [13]. The principle of image warping is the following. Let $I_{1}$ be the image to be warped, in our case the image of the leg wearing compression socks. Let $I$ denote the warped image, i.e., a synthetic image derived from $I_{1}$ by mathematical operations. Actually, the mathematical operations consist here in applying onto $I_{1}$ a geometric deformation. The principles are the following.

1. Let $u(x, y)$ and $v(x, y)$ be, respectively, the two components of the geometric deformation; $x$ and $y$ denote the plane coordinates of a pixel of the warped image where the gray level has to be estimated. Let $i(x, y)$ denote this gray level.

2. Assuming that the gray level of each material point remains constant between the unloaded and loaded states, it can be stated that $i(x, y)$ should be the same as $i_{1}(x+u, y+v)$ which denotes the gray level at $(x+u, y+v)$ in $I_{1}$.

3. As $(x+u, y+v)$ is usually not the exact position of a pixel in $I_{1}, i(x, y)$ is derived by linear interpolation from the gray levels of the pixels surrounding $(x+u, y+v)$ in $I_{1}$. 
Eventually, the objective is that $I$ matches as correctly as possible the target image, denoted $I_{0}$, which is the image of the uncompressed leg in our case. To this aim, an optimization method based on the Nelder-Mead algorithm was coded in MATLAB ${ }^{\circledR}$. Image warping was achieved still using MATLAB ${ }^{\circledR}$ with a custom made routine [12].

\subsection{Results}

Identified constitutive parameters. The identified Young's moduli are $19.4 \mathrm{kPa}$ and $62.4 \mathrm{kPa}$, and Poisson ratios are 0.46 and 0.36 for fat and muscles, respectively.

Hydrostatic pressure field. The hydrostatic pressure field inside the leg emphasizes a heterogeneous pressure distribution inside the leg (Fig. 2). Fat is subjected to more pressure than muscles. The maximum pressure is located where the curvature radius is less: near the tibia (in front of the leg) and on the gastrocnemius muscles.

Vertical variation of pressure. Fig. 3 shows the hydrostatic pressure as a function of height at the main deep and superficial vein locations, and the applied pressure. Even if the latter is progressive, the vein pressure depends on the location.

In calf, the two great superficial veins are near surfaces where the curvature radius are large so

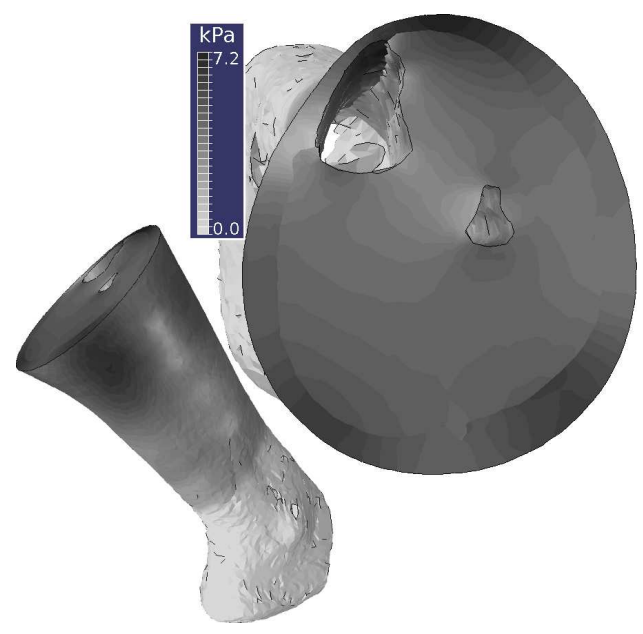

Figure 2: Hydrostatic pressure field inside the leg. the pressure is weak. The deep vein pressure is low, too, due to the effects of surrounding tissues and bones. Its value is close but inferior to the superficial vein pressure.

In ankle until the beginning of the gastrocnemius muscles, the vein pressure is greater than the mean applied pressure (1 $\mathrm{kPa}$ more).

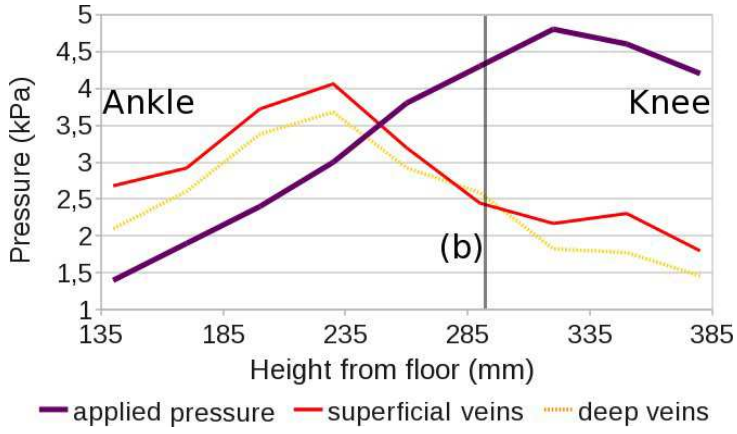

(a)

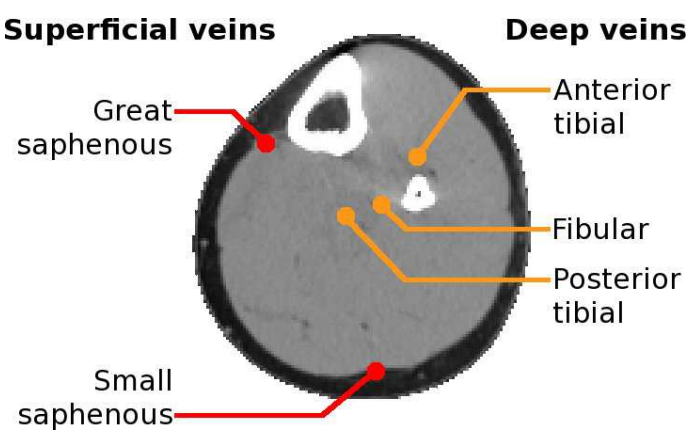

(b)

Figure 3: Mean computed hydrostatic pressure as a function of height (a). Main deep and superficial vein locations (b).

\subsection{Discussion}

Comparison of $2 D$ and $3 D$ models. The 2D plane strain model which lead to identifying the material properties was compared to the $3 \mathrm{D}$ model. To this aim, the $2 \mathrm{D}$ model was reconstructed with the same pressure boundary conditions and the same geometry as the 
3D model.

Hydrostatic pressure was compared at main vein locations and no significant differences were observed between the two models (less than $9 \%$ ), which confirms the validity of the 2D model for identifying the material properties.

Consequence of non homogeneous pressure. Currently, the choice of a compression sock is based only on the calf size and on the disease significance. But, as the pressure is non homogeneous inside the leg under compression, it should be also adapted to the location of the diseased veins.

The pressure field depends on leg geometry. It will be interesting to apply this model on other patients with different morphologies.

Hydrostatic pressure. The current study provides an answer to the general question of pressure transmission through internal tissues. The current model shows that the spatial variations of pressure are significant inside the leg and, consequently, pressure transmission through the internal tissues should be considered in medical treatments.

The mechanical role of veins is neglected. Therefore the pressure applied onto the vein walls is assumed to be the same as pressure in the surrounding tissues. This assumption is not evaluated in the current study. A more sophisticated model involving fluid structure interactions will be set up in the future to address this issue. Another limitation is the effect of aponeuroses on the distribution pressure.

Material properties. Soft tissue properties are assumed isotropic. This assumption is accurate for fat. But muscles are made up of fibres and are enclosed by aponeuroses which means the muscle properties is instead transversely isotropic.

\section{CONCLUSION}

In the present work, a 3D FE model of the compressed leg was presented. The material properties were determined thanks to an inverse identification method based on a 2D model. The results show that hydrostatic pressure distribution is heterogeneous inside the leg. Thus the pressure applied on the leg is different from the vein pressure. The latter depends on the leg geometry. The characterization of a correction factor for the pressure transmitted to veins, dependent on patient morphology, could help physicians to choose the compression socks.

\section{WORK IN PROGRESS}

Currently, the objective is to get closer to the actual conditions by

- calibrating the 3D model against the 3D CT-scans,

- apply the method to other patients in order to understand the effect of the leg morphology

Future work will be to consider the aponeuroses and to use transversely isotropic properties for the muscles. 


\section{References}

1. Dai X.Q., Liu R., Li Y., Zhang M. and Kwok Y.L., Numerical simulation of skin pressure distribution applied by graduated compression stockings, Stud. Comp. Intell., 2007, Vol. 55, 301-309.

2. Li Y., Zhang X. and Yeung K. W., A 3D biomechanical model for numerical simulation of dynamique mechanical interactions of bra and breast during wear, Sen'i Gakkaishi, 2003, Vol. 59, 12-21.

3. You F., Wang J.-M. and Liao G.-J., The simulation of elastic human body deformation and garment pressure with moving mesh method, Stud. Comp. Intell., 2007, Vol. 55, $289-300$.

4. Zhang M., Dai X. Q., Li Y. and Cheung J. T.-M., Computational simulation of skin and sock pressure distributions, Comput. Intell., 2007, Vol. 55, 323 - 333.

5. Aubert J.-T., Bassez S., Louisy F. and Ribreau Ch., Accélérations dans le réseau veineux du membre inférieur au cours de la marche stationnaire, In XVème Congrès Francais de Mécanique, Centre Universitaire Marseille Saint-Charles, 2001.

6. Downie S. P., Raynor Sh. M., Firmin D. N., Wood N. B., Thom S. A., Hughes A. D., Parker K. H., Wolfe J. H. N. and Yun Xu X., Effects of elastic compression stockings on wall shear stress in deep and superficial veins of the calf, Am. J. Physiol.-Heart C., 2008, H2112-H2120.

7. Guesdon, P., Fullana, J.-M. and Flaud, P., Étude expérimentale du drainage musculaire, C. R. Mec., 2007, Vol. 335, 207-212.

8. van Donkelaar C. C., Huyghe J. M., Vankan W. J. and Drost M. R., Spatial interaction between tissue pressure and skeletal muscle perfusion during contraction, J. Biomech., 2001, Vol. 34, 631 - 637.

9. BVSport ${ }^{\circledR}$, www.bvsport.com.

10. AFNOR, NF G30-102, Article de bonneterie - Détermination de la pression de contention, 1986.

11. Bouten L., Identification des propriétés mécaniques des tissus constitutifs du mollet pour l'étude mécanique de la contention, $\mathrm{PhD}$ thesis, École Nationale Supérieure des Mines de Saint-Étienne, 2009.

12. Avril S., Bouten L., Dubuis L., Drapier S. and Pouget J.-F., Mixed experimental and numerical approach for characterizing the biomechanical response of the human leg under elastic compression, ASME J. Biomech. Engrg., 2010, Vol. 132, 031006-1-8.

13. Chung J. H., Rajagopal V., Nielsen P. M. F. and Nash M. P., A biomechanical model of mammographic compressions, Biomech. Model. Mechanobiol., 2007, Vol. 7, 43-52. 